\title{
Mild Silver-Mediated Geminal Difluorination of Styrenes Using an Air- and Moisture-Stable Fluoroiodane Reagent**
}

\author{
Nadia O. Ilchenko, Boris O. A. Tasch, and Kálmán J. Szabó*
}

\begin{abstract}
An air- and moisture-stable fluoroiodane in the presence of $\mathrm{AgBF}_{4}$ is suitable for selective geminal difluorination of styrenes under mild reaction conditions. One of the $C-F$ bonds is formed by transfer of electrophilic fluorine from the hypervalent iodine reagent, while the other one arises from the tetrafluoroborate counterion of silver. Deuterium-isotopelabelling experiments and rearrangement of methyl styrene substrates suggest that the reaction proceeds through a phenonium ion intermediate.
\end{abstract}

rganofluorines are very important substances in pharmaceutical and agrochemical industries and have also had an increasing role in medicinal research and diagnostics. ${ }^{[1]}$ As organofluorine compounds are specific regulator substances, inhibitors, or biomarkers, constant development of new methodologies for their selective synthesis is a very important task in synthetic chemistry. The appearance of new stable, electrophilic fluorinating reagents and methodologies allowed the extension of the new methodologies for selective synthesis of a large variety of organofluorine compounds. ${ }^{[2]}$ In recent years creation of single $\mathrm{C}-\mathrm{F}$ bonds, introduction of $\mathrm{CF}_{2}$, and trifluoromethylation reactions have received a lot of attention. Of these major areas the introduction of a $\mathrm{CF}_{2}$ group is probably the least developed. ${ }^{[3]}$ Nevertheless, the difluoromethyl group proved to be an important motif in enzyme inhibitors. ${ }^{[4]}$ This property is probably a result of the ability of the $\mathrm{CF}_{2} \mathrm{H}$ group to donate hydrogen bonds,${ }^{[5]}$ and, thus serve as a bioisoster for hydroxy and thiol moieties. ${ }^{[6]}$ Furthermore, very recently $\mathrm{CF}_{2}$ groups have found new applications in medicinal diagnostics as well. A new trend in the synthesis of trifluoromethyl-group-based PET tracers is substitution of suitable $\mathrm{sp}^{3}$ difluoromethyl groups with ${ }^{18} \mathrm{~F}$ to obtain ${ }^{18} \mathrm{FCF}_{2}$ functionalities. ${ }^{[7]}$

The early methods for introducing difluoromethyl groups to organic molecules were mainly based on the application of

[*] N. O. Ilchenko, Dr. B. O. A. Tasch, Prof. K. J. Szabó Department of Organic Chemistry, Stockholm University

E-mail:kalman@organ.su.se Homepage: http://www.organ.su.se/ks/

[***] Support by the Swedish Research Council and the Knut and Alice Wallenbergs Foundation, as well as a post-doctoral fellowship for B. O. A. T. by the Tryggers foundation is gratefully acknowledged.

Supporting information for this article is available on the WWW under http://dx.doi.org/10.1002/anie.201408812.

of (c) 2014 The Authors. Published by Wiley-VCH Verlag GmbH \& Co. $\mathrm{KGaA}$. This is an open access article under the terms of the Creative Commons Attribution Non-Commercial License, which permits use, distribution and reproduction in any medium, provided the original work is properly cited and is not used for commercial purposes. highly reactive inorganic fluorinating reagents, such as DAST, ${ }^{[8]}$ Deoxofluor, ${ }^{[9]}$ and $\mathrm{XeF}_{2}{ }^{[10]}$ However, application of these reagents may lead to problems in functional-group tolerance and selectivity, and causes hazardous HF development upon contact with water. The recently reported methodologies are usually based on metal-catalyzed cross-coupling of various $\mathrm{CF}_{2}$ carriers with aryl halides and boronates. For example the groups of Amii, ${ }^{[11]}$ Hartwig, ${ }^{[12]}$ Prakash and Olah, ${ }^{[13]}$ and Qing ${ }^{[14]}$ used a copper catalyst (or mediator), while the group of Zhang ${ }^{[15]}$ used palladium catalysis for the introduction of a $\mathrm{CF}_{2}$ group to organic substrates. Baran and co-workers have published a series of papers on $\mathrm{C}-\mathrm{H}$ difluoromethylation by $\mathrm{CF}_{2} \mathrm{H}$ radicals. ${ }^{[16]}$ Introduction of the difluoromethyl group with consecutive difluorination reactions is a less common approach compared to the abovementioned cross-coupling of $\mathrm{CF}_{2}$ units with the organic substrate. Tang and co-workers ${ }^{[17]}$ have shown that consecutive geminal difluorination of aromatic benzyl groups can be achieved by using Selectfluor as a fluorine source in combination with a silver catalyst under oxidative conditions. A similar reaction has been reported by Chen and coworkers $^{[18]}$ using visible-light-promoted reactions under metal-free conditions. For both reactions a radical mechanism was postulated.

Recently, development of new fluorination reactions by application of hypervalent iodine reagents has attracted considerable attention. ${ }^{[2 a, b, 19]}$ As a part of our synthetic fluorochemistry program, ${ }^{[20]}$ we have studied the potential use of the hypervalent fluoroiodane $\mathbf{1}^{[19 f, 21]}$ as an electrophilic organofluorinating reagent [see Eq. (1)]. The fluoroiodane $\mathbf{1}$ is an air- and moisture-stable crystalline compound and structural analogue of the Togni reagent, ${ }^{[2 a, 22]}$ which has been one of the most successful electrophilic trifluoromethylating reagents in organic synthesis. Another attractive property is that 1 can be obtained from its chloro analogue by addition of KF. ${ }^{[21 b]}$ Thus, synthesis of $\mathbf{1}$ using KF involves a simple umpolung method by changing a nucleophilic fluorine into an electrophilic one. This simple possibility for umpolung of the fluorine atom can be a useful feature for the development of new tracers for medicinal diagnostics. ${ }^{[23]}$ The first report by Legault and Prévost ${ }^{[21 a]}$ on the attempts to use $\mathbf{1}$ for $\mathrm{C}-\mathrm{F}$ bond-formation reactions was disappointing. In contrast to its bromo analogue, $\mathbf{1}$ was not suitable for the electrophilic halogenation of anisole. According to Stuart and co-workers $^{[19 f]} 1$ reacts with 1,3-diketoesters and 1,3-diketones in the presence of TREAT-HF to give mono- and difluoro products, respectively. As far as we know, this paper by Stuart and coworkers ${ }^{[19 f]}$ has been the only report on the application of 1 for creating $\mathrm{C}-\mathrm{F}$ bonds. 
We have now found [Eq. (1)] that mixing of equimolar amounts of the styrene $\mathbf{2 a}, \mathbf{1}$, and $\operatorname{AgBF}_{4}(\mathbf{3})$ results in the difluoro compound $\mathbf{4 a}$ under mild reaction conditions $\left(40^{\circ} \mathrm{C}\right)$. The reaction was very clean and the yield of the isolated product was over $50 \%$, thus indicating that in the geminally difluorinated product one of the fluorine atoms was derived from $\mathbf{1}$, while the other one originated from the $\mathrm{BF}_{4}{ }^{-}$ counterion of silver. Thus, under mild reaction conditions, using air- and moisture-stable starting materials a formal $\mathrm{F}_{2}$ addition to $\mathbf{2}$ a could be performed.<smiles>C=Cc1ccc(-c2ccccc2)cc1</smiles>

2a

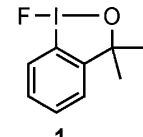

1

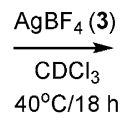
$40^{\circ} \mathrm{C} / 18 \mathrm{~h}$<smiles>FC(F)Cc1ccc(-c2ccccc2)cc1</smiles>

Deviation from the above mentioned [Eq. (1)] optimal reaction conditions led to either lower yields of isolated $4 \mathbf{a}$ or no reaction of $\mathbf{2} \mathbf{a}$ (Table 1). Application of catalytic amounts

Table 1: Variation of the yield of the isolated product resulting from changes to the reaction conditions [see Eq. (1)].

\begin{tabular}{llc}
\hline Entry & $\begin{array}{l}\text { Deviation from the reaction conditions given in } \\
\text { Equation }(1)\end{array}$ & Yield [\%] \\
\hline 1 & 10 mol\% $\mathrm{AgBF}_{4}$ & 36 \\
2 & 1 equiv $\mathrm{AgSbF}_{6}$ & 18 \\
3 & 1 equiv $\mathrm{AgOAc}, \mathrm{AgCN}$ and $\mathrm{AgF}$ & $<5$ \\
4 & 10 mol\% $\mathrm{AgOAc}, 1$ equiv $\mathrm{Bu}_{4} \mathrm{NBF}_{4}$ & $<5$ \\
5 & 10 mol\% $\mathrm{AgOAc}_{1} 1$ equiv $(t \mathrm{Bu})_{3} \mathrm{PHBF}_{4}$ & 44 \\
6 & 1 equiv $\mathrm{AgBF} \mathrm{BH}_{4}, 1$ equiv Selectfluor instead of 1 & $<5$ \\
7 & 1 equiv $\mathrm{Zn}\left(\mathrm{BF}_{4}\right)_{2}$ & 46 \\
8 & 1 equiv $\mathrm{Cu}\left(\mathrm{MeCN}_{4} \mathrm{BF}_{4}\right.$ & 32 \\
9 & 1 equiv $\mathrm{ZnF}_{2}, \mathrm{CuF}_{2}$ & $<5$ \\
10 & MeOH as solvent & $<5$ \\
11 & toluene as solvent & trace \\
\hline
\end{tabular}

of $\mathrm{AgBF}_{4}$, instead of 1 equivalent, led to a significant drop in yield from 73 to $36 \%$ (entry 1 ). Using $\mathrm{AgSbF}_{6}$ as a mediator and $\mathrm{F}$ source led to formation of $\mathbf{4 a}$ (entry 2 ) but the reaction was much slower than that with $\mathrm{AgBF}_{4}$, as a lot of unreacted starting material (2a) remained. When $\mathrm{AgOAc}, \mathrm{AgCN}$, or $\mathrm{AgF}$ was applied instead of $\mathbf{3}$ the styrene $\mathbf{2}$ a remained intact (entry 3). A combination of catalytic amounts of AgOAc and 1 equivalent $\mathrm{Bu}_{4} \mathrm{NBF}_{4}$ was inefficient (entry 4), but upon treatment with $(t \mathrm{Bu})_{3} \mathrm{PHBF}_{4}$, instead of $\mathrm{Bu}_{4} \mathrm{NBF}_{4}, \mathbf{4 a}$ was isolated with $44 \%$ yield (entry 5 ). This result and the above experiment (entry 1 ) with a catalytic amount of $\mathbf{3}$ indicate that the geminal difluorination reaction can be achieved with a catalytic amount of a silver salt. Thus, the source of the second fluoride [Eq. (1)] is the $\mathrm{BF}_{4}{ }^{-}$, which must not necessarily be added as part of a silver salt. However, the yields of $\mathbf{4}$ are much higher with stoichiometric amounts of $\mathrm{AgBF}_{4}$. Therefore, we employed one equivalent of $\mathrm{AgBF}_{4}$ as a mediator and secondary fluorine source in additional applications (see also Table 2). When we replaced $\mathbf{1}$ with Selectfluor, fluorination of $\mathbf{2 a}$ was not observed (entry 6). In the case of using $\mathrm{Zn}\left(\mathrm{BF}_{4}\right)_{2}$ or $\mathrm{Cu}(\mathrm{MeCN})_{4} \mathrm{BF}_{4}$, instead of $\mathrm{AgBF}_{4}$, we could observe the difluorination reaction and isolate $4 \mathbf{a}$ in the corresponding yields of 46 and $32 \%$.
However, particularly with a copper salt, several other byproducts were formed (entries 7 and 8).

The reaction with palladium salts was rather interesting. $\left[\mathrm{Pd}(\mathrm{MeCN})_{4}\left(\mathrm{BF}_{4}\right)_{2}\right]$ proved to be a rather efficient catalyst, thus affording $\mathbf{4 a}$ with $50 \%$ yield [Eq. (2)]. However, when

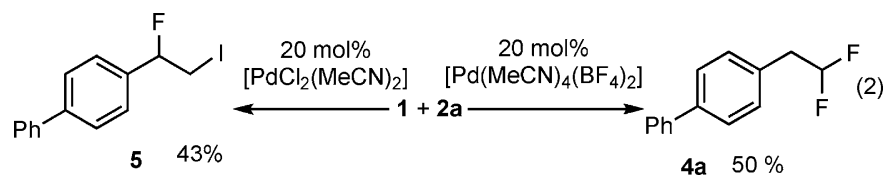

the $\mathrm{BF}_{4}^{-}$counter ion exchanged to $\mathrm{Cl}^{-}$the outcome of the reaction was completely different. When using $\left[\mathrm{PdCl}_{2}-\right.$ $(\mathrm{MeCN})_{2}$ ] as the catalyst $\mathbf{4 a}$ did not form at all but the reaction gave the iodofluorinated product $\mathbf{5}$, which could be isolated with $43 \%$ yield. Further studies indicated that in the geminal difluorination reaction with $\mathbf{1}, \mathrm{AgF}, \mathrm{ZnF}_{2}$, or $\mathrm{CuF}_{2}$ were not able to serve as fluoride sources (Table 1, entries 3 and 9). We employed $\mathrm{CDCl}_{3}$ as the solvent, which allowed the careful analysis of the crude reaction mixtures by ${ }^{1} \mathrm{H}$ and ${ }^{19}$ F NMR spectroscopy. Change of the solvent to $\mathrm{MeOH}$ or THF completely hindered any transformation of $\mathbf{2 a}$ (entry 10), while using toluene led to formation of only traces of $\mathbf{4 a}$ (entry 11).

Subsequently, we studied the synthetic scope of the reaction (Table 2). Both $\alpha$ - and $\beta$-naphtyl styrenes ( $2 \mathbf{b}$ and 2c) underwent geminal difluorination with high yields (entries 2 and 3). Despite the use of stoichiometric amounts of $\mathrm{AgBF}_{4}$ the bromo substituent in $\mathbf{2 d}$ was tolerated and $\mathbf{4 d}$ was formed in a clean difluorination process (entry 4). The compound $4 \mathbf{d}$ can be a useful intermediate for modular synthesis of difluoromethyl compounds, as the bromo functionality can easily transformed by Suzuki-Miyaura coupling. ${ }^{[2]}$ The difluorination reaction also tolerates oxygencontaining substituents, such as the ether in $\mathbf{2 e}$ and carboxylate in $\mathbf{4 f}$ (entries 5 and 6). However, for these substrates, we obtained somewhat lower yields than those for the hydrocarbon substrates $\mathbf{2} \mathbf{a}-\mathbf{c}$. The parent styrene $\mathbf{2} \mathbf{g}$ reacted readily with $\mathbf{1}$ but the isolation of $\mathbf{4} \mathbf{g}$ was difficult because of its volatility. Therefore, we determined the yield of $\mathbf{4} \mathbf{g}$ by ${ }^{1}$ H NMR spectroscopy. meta-Phenyl (2h) and bromo (2i) styrenes reacted readily to provide the corresponding difluorinated compounds $\mathbf{4 h}$ and $\mathbf{4 i}$ (entries 8 and 9). However, our attempts to obtain geminal difluorinated products from ortho-substituted styrenes remained fruitless. The reactions with the $\alpha$-methyl styrenes $\mathbf{2} \mathbf{j}-\mathbf{l}$ gave surprising results. We still obtained the $\beta$-difluorinated products $4 \mathbf{j}-\mathbf{l}$ but the methyl group migrated from the $\alpha$ - to the $\beta$-position (entries 10-12). The rearrangement proceeds very cleanly, as we could not observe any other isomers of $\mathbf{4} \mathbf{j}-\mathbf{l}$ in the crude reaction mixture.

This finding and the fact that one of the fluorines arises from an electrophilic source (from 1) and the other from a nucleophilic reagent (from a $\mathrm{BF}_{4}^{-}$anion) suggests a very interesting mechanism for the geminal difluorination process. To explore the mechanism, we prepared the deutero analogue of $\mathbf{2} \mathbf{a},\left[D_{2}\right]-\mathbf{2} \mathbf{a}$. When $\left[D_{2}\right]-\mathbf{2} \mathbf{a}$ was reacted with $\mathbf{1}$ in the 
Table 2: Difluorination of styrene derivatives with the iodiane 1 and $\mathrm{AgBF}_{4} \cdot{ }^{[\mathrm{a}]}$

\begin{tabular}{|c|c|c|c|}
\hline Entry & Substrate & Product & Yield $[\%]^{[}$ \\
\hline 1 & & & 73 \\
\hline 2 & & & 72 \\
\hline 3 & & & 88 \\
\hline 4 & & & 72 \\
\hline 5 & & & 55 \\
\hline 6 & & & 65 \\
\hline 7 & & & $77^{[\mathrm{c}]}$ \\
\hline 8 & & & 60 \\
\hline 9 & & & 54 \\
\hline 10 & & & 65 \\
\hline 11 & & & 59 \\
\hline 12 & & & 52 \\
\hline
\end{tabular}

[a] Styrene $2(0.1 \mathrm{mmol}), 1(0.1 \mathrm{mmol})$, and $\mathrm{AgBF}_{4}(0.1 \mathrm{mmol})$ in chloroform $(0.5 \mathrm{~mL})$ was stirred at $40^{\circ} \mathrm{C}$ for $18 \mathrm{~h}$. [b] Unless otherwise stated yield is that of isolated product. [c] Yield determined by NMR spectroscopy.

presence of $\mathrm{AgBF}_{4}$ under the usual reaction conditions the compound $\left[\mathrm{D}_{2}\right] \mathbf{- 4 a}$ was obtained in a very clean reaction [Eq. (3)]. This outcome was a surprising result, since the shift

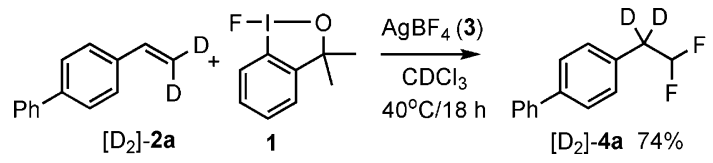

of one of the deuterium atoms of $\left[\mathrm{D}_{2}\right]-\mathbf{2} \mathbf{a}$ was expected. The double deuterium shift suggested a significant deuterium isotope effect. Therefore, we performed a competitive difluorination reaction between $2 \mathbf{a}$ and $\left[\mathrm{D}_{2}\right]-\mathbf{2} \mathbf{a}$ [Eq. (4)]. However, according to these studies the deuterium isotope effect was found to be weak (about 1.3).

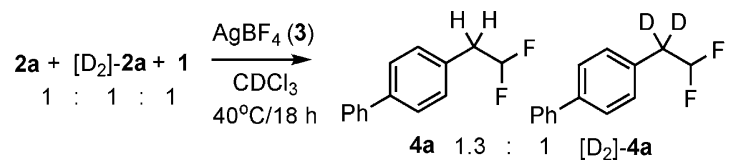

The above results indicate that the hydrogen shift from the $\alpha$ - to the $\beta$-position of styrene is unlikely. We reasoned that the difluorination reaction probably proceeds by an $\alpha$ - to $\beta$-carbon atom exchange of the styrene derivative through a possible phenonium ion intermediate. Such types of intermediates were first suggested by $\mathrm{Cram}^{[25]}$ and subsequently observed by Olah and co-workers. ${ }^{[26]}$

Accordingly, our plausible mechanism (Figure 1) involves silver-activated addition of the iodane to the double bond of $\left[\mathrm{D}_{2}\right]-\mathbf{2} \mathbf{a}$ to give the iodonium ion 6. Togni and co-workers ${ }^{[27]}$ studied the activation of the $\mathrm{CF}_{3}$ analogue of $\mathbf{1}$ using zinc salts.

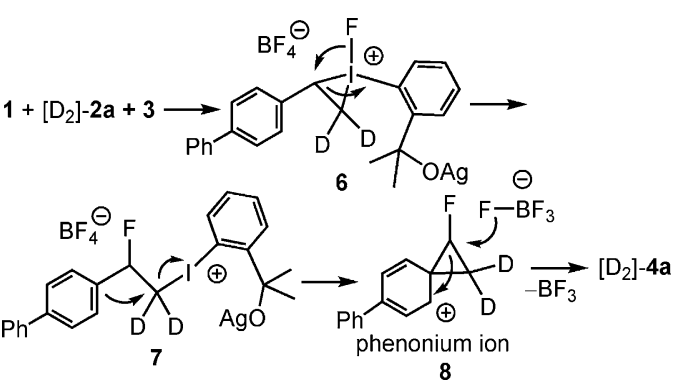

Figure 1. Plausible mechanism for the geminal difluorination of styrenes.

A similar metal-mediated activation is conceivable for $\mathbf{1}$ as well. As mentioned above (Table 1, entry 7) $\mathrm{Zn}\left(\mathrm{BF}_{4}\right)_{2}$ is also a viable mediator of the difluorination process. Moreover, suitable copper and palladium salts [Table 1, entry 8 and Eq. (2)] may have a similar activating effect. The electron deficiency of iodine in $\mathbf{6}$ can be relieved by fluorine migration to give $\mathbf{7}$. The $\pi$ donation of the aromatic ring in $\mathbf{7}$ may result in formation of the phenonium ion 8. In this process the iodoaryl group arising from $\mathbf{1}$ serves as a leaving group. The positive charge may delocalize over five carbon atoms (for sake of clarity only one of the resonance structures is given in Figure 1).

By using the $\left[\mathrm{PdCl}_{2}(\mathrm{MeCN})_{2}\right]$ catalyst [Eq. (2)] the faith of 7 was probably different and it underwent $\mathrm{C}\left(\mathrm{sp}^{2}\right)-\mathrm{I}$ bond fission to result in $\mathbf{5}$. The only possible source of iodine in $\mathbf{5}$ is 1. However, in the case of $\mathrm{AgBF}_{4}$ (or a few other catalysts or mediators) the fluorinated phenonium ion $\mathbf{8}$ forms (Figure 1), and may undergo a second fluorination by a nucleophilic fluorine arising from the $\mathrm{BF}_{4}^{-}$. The $\mathrm{BF}_{4}^{-}$anion is an unexpected but not unusual source of nucleophilic fluoride. 
Our recent studies ${ }^{[28]}$ have shown the $\mathrm{BF}_{4}{ }^{-}$from $\left[\mathrm{Pd}(\mathrm{MeCN})_{4^{-}}\right.$ $\left(\mathrm{BF}_{4}\right)_{2}$ ] [see Eq. (2)] may serve as a fluorine source in the activation of $\left(\mathrm{SiMe}_{3}\right)_{2}$ for catalytic silylation of allyl alcohols. Gandon and co-workers ${ }^{[29]}$ have recently shown that $\mathrm{BF}_{4}{ }^{-}$ from $\mathrm{AgBF}_{4}$ is an excellent fluorinating reagent for organometallic compounds. The present study is probably one of the few examples demonstrating that a $\mathrm{C}-\mathrm{F}$ bond can also be formed under mild reaction conditions using $\mathrm{BF}_{4}^{-}$as a fluorine source. An additional remarkable feature of the abovepresented reaction is that the opening of the cyclopropyl ring of $\mathbf{8}$ is highly regioselective. We could not observe formation of $\alpha$-, $\beta$-difluorinated regioisomers of $4 \mathbf{a}$ in the ${ }^{1} \mathrm{H}$ and ${ }^{19} \mathrm{~F}$ NMR spectra of the crude reaction mixtures. Opening of the cyclopropane ring of the fluorinated carbon in $\mathbf{8}$ also easily explains the apparent migration of the methyl group in the difluorination of $\mathbf{2} \mathbf{j}-\mathbf{- l}$ (entries 10-12 in Table 2). A further confirmation of the plausible mechanism in Figure 1 could be the analogue reactivity of phenyl iodonium acetate (PIDA) or phenyl iodonium trifluoroacetate (PIFA) with styrene derivatives. PIDA and PIFA can be considered structural analogues of 1. Tellitu and Domínguez, ${ }^{[30]}$ and the group of Wirth ${ }^{[31]}$ also postulated that the dioxo substitution of styrenes with PIDA and PIFA probably proceeds via phenonium intermediates.

In summary, we have shown that the hypervalent iodine 1 and $\mathrm{AgBF}_{4}$ (and a few other metal tetrafluoroborates) induce geminal difluorination of styrenes. These air- and moisture-stable reagents react under mild reaction conditions to perform a selective formal $\mathrm{F}_{2}$ addition. Using equimolecular amounts of $\mathbf{1}$ and styrene derivatives resulted in yields over $50 \%$, thus indicating that one of the $\mathrm{C}-\mathrm{F}$ bonds is created by electrophilic fluorinating reagent $\mathbf{1}$, while the other one results from fluorine transfer from $\mathrm{BF}_{4}{ }^{-}$. The deuteriumlabelling experiments indicate that the process probably proceeds via phenonium intermediates. The reaction is suitable for mild synthesis of $\beta$-difluoro aromatic compounds, which are bioisosters ${ }^{[4-6]}$ of natural compounds with benzylalcohol and thiol motifs. In addition, our method extends the scope of the fluorination reactions, including a new application of the easily accessible, stable, and safe electrophilic fluoroidane reagent $\mathbf{1}$.

\section{Experimental Section}

The iodane 1 (28.0 mg, $0.1 \mathrm{mmol}), \mathrm{AgBF}_{4} 3(19.4 \mathrm{mg}, 0.1 \mathrm{mmol})$, and the styrene $2\left(0.1 \mathrm{mmol}, 1\right.$ equiv) were mixed in $\mathrm{CDCl}_{3}(0.5 \mathrm{~mL})$ and this mixture was stirred at $40^{\circ} \mathrm{C}$ for $18 \mathrm{~h}$. Then product 4 was isolated by chromatography.

Received: September 4, 2014

Revised: October 2, 2014

Published online: October 21, 2014

Keywords: fluorine - hypervalent compounds . reaction mechanism $\cdot$ rearrangement $\cdot$ silver

[1] a) K. Müller, C. Faeh, F. Diederich, Science 2007, 317, 1881; b) S. Purser, P. R. Moore, S. Swallow, V. Gouverneur, Chem. Soc. Rev. 2008, 37, 320; c) M. Tredwell, S. M. Preshlock, N. J. Taylor, S.
Gruber, M. Huiban, J. Passchier, J. Mercier, C. Génicot, V. Gouverneur, Angew. Chem. Int. Ed. 2014, 53, 7751; Angew. Chem. 2014, 126, 7885; d) P. Jeschke, ChemBioChem 2004, 5, 570; e) J. Wang, M. Sánchez-Roselló, J. L. Aceña, C. del Pozo, A. E. Sorochinsky, S. Fustero, V. A. Soloshonok, H. Liu, Chem. Rev. 2014, 114, 2432.

[2] a) J. Charpentier, N. Früh, A. Togni, Chem. Rev. 2014, DOI: 10.1021/cr500223h; b) T. Liang, C. N. Neumann, T. Ritter, Angew. Chem. Int. Ed. 2013, 52, 8214; Angew. Chem. 2013, 125, 8372; c) H. Egami, M. Sodeoka, Angew. Chem. Int. Ed. 2014, 53, 8294; Angew. Chem. 2014, 126, 8434; d) P. Chen, G. Liu, Synthesis 2013, 2919; e) E. Merino, C. Nevado, Chem. Soc. Rev. 2014, 43, 6598.

[3] J. Hu, W. Zhang, F. Wang, Chem. Commun. 2009, 7465.

[4] a) R. Aráoz, E. Anhalt, L. René, M.-A. Badet-Denisot, P. Courvalin, B. Badet, Biochemistry 2000, 39, 15971; b) H. R. Hope, D. Heuvelman, K. Duffin, C. Smith, J. Zablocki, R. Schilling, S. Hegde, L. Lee, B. Witherbee, M. Baganoff, C. Bruce, A. R. Tall, E. Krul, K. Glenn, D. T. Connolly, J. Lipid Res. 2000, 41, 1604; c) F. Narjes, K. F. Koehler, U. Koch, B. Gerlach, S. Colarusso, C. Steinkühler, M. Brunetti, S. Altamura, R. De Francesco, V. G. Matassa, Bioorg. Med. Chem. Lett. 2002, 12, 701; d) Y. Xu, L. Qian, A. V. Pontsler, T. M. McIntyre, G. D. Prestwich, Tetrahedron 2004, 60, 43; e) Y. Xu, G. D. Prestwich, J. Org. Chem. 2002, 67, 7158.

[5] J. A. Erickson, J. I. McLoughlin, J. Org. Chem. 1995, 60, 1626.

[6] N. A. Meanwell, J. Med. Chem. 2011, 54, 2529.

[7] a) S. Mizuta, I. S. R. Stenhagen, M. O’Duill, J. Wolstenhulme, A. K. Kirjavainen, S. J. Forsback, M. Tredwell, G. Sandford, P. R. Moore, M. Huiban, S. K. Luthra, J. Passchier, O. Solin, V. Gouverneur, Org. Lett. 2013, 15, 2648; b) P. J. Riss, T. Ruehl, W. Rafique, V. T. Lien, Chem. Commun. 2014, 50, 0; c) D. van der Born, C. Sewing, J. D. M. Herscheid, A. D. Windhorst, R. V. A. Orru, D. J. Vugts, Angew. Chem. Int. Ed. 2014, 53, 11046; Angew. Chem. 2014, 126, 11226.

[8] a) R. P. Singh, J. n. M. Shreeve, Synthesis 2002, 2561; b) W. R. Dolbier, P. Xie, L. Zhang, W. Xu, Y. Chang, K. A. Abboud, J. Org. Chem. 2008, 73, 2469.

[9] W. J. Middleton, J. Org. Chem. 1975, 40, 574.

[10] T. B. Patrick, S. Qian, Org. Lett. 2000, 2, 3359.

[11] K. Fujikawa, Y. Fujioka, A. Kobayashi, H. Amii, Org. Lett. 2011, 13, 5560.

[12] P. S. Fier, J. F. Hartwig, J. Am. Chem. Soc. 2012, 134, 5524.

[13] G. K. S. Prakash, S. K. Ganesh, J.-P. Jones, A. Kulkarni, K. Masood, J. K. Swabeck, G. A. Olah, Angew. Chem. Int. Ed. 2012, 51, 12090; Angew. Chem. 2012, 124, 12256.

[14] X.-L. Jiang, Z.-H. Chen, X.-H. Xu, F.-L. Qing, Org. Chem. Frontiers 2014, 1, 774.

[15] Z. Feng, Q.-Q. Min, Y.-L. Xiao, B. Zhang, X. Zhang, Angew. Chem. Int. Ed. 2014, 53, 1669; Angew. Chem. 2014, 126, 1695.

[16] a) Y. Fujiwara, J. A. Dixon, F. O'Hara, E. D. Funder, D. D. Dixon, R. A. Rodriguez, R. D. Baxter, B. Herle, N. Sach, M. R. Collins, Y. Ishihara, P. S. Baran, Nature 2012, 492, 95; b) Y. Fujiwara, J. A. Dixon, R. A. Rodriguez, R. D. Baxter, D. D. Dixon, M. R. Collins, D. G. Blackmond, P. S. Baran, J. Am. Chem. Soc. 2012, 134, 1494; c) Q. Zhou, A. Ruffoni, R. Gianatassio, Y. Fujiwara, E. Sella, D. Shabat, P. S. Baran, Angew. Chem. Int. Ed. 2013, 52, 3949; Angew. Chem. 2013, $125,4041$.

[17] P. Xu, S. Guo, L. Wang, P. Tang, Angew. Chem. Int. Ed. 2014, 53, 5955; Angew. Chem. 2014, 126, 6065.

[18] J.-B. Xia, C. Zhu, C. Chen, J. Am. Chem. Soc. 2013, 135, 17494.

[19] a) M. Tredwell, V. Gouverneur, Angew. Chem. Int. Ed. 2012, 51, 11426; Angew. Chem. 2012, 124, 11590; b) S. Suzuki, T. Kamo, K. Fukushi, T. Hiramatsu, E. Tokunaga, T. Dohi, Y. Kita, N. Shibata, Chem. Sci. 2014, 5, 2754; c) W. Kong, P. Feige, T. de Haro, C. Nevado, Angew. Chem. Int. Ed. 2013, 52, 2469; 
Angew. Chem. 2013, 125, 2529; d) B. H. Rotstein, N. A. Stephenson, N. Vasdev, S. H. Liang, Nat. Commun. 2014, 5, 4365; e) T. Kitamura, S. Kuriki, M. H. Morshed, Y. Hori, Org. Lett. 2011, 13, 2392; f) G. C. Geary, E. G. Hope, K. Singh, A. M. Stuart, Chem. Commun. 2013, 49, 9263.

[20] a) P. G. Janson, I. Ghoneim, N. O. Ilchenko, K. J. Szabó, Org. Lett. 2012, 14, 2882; b) N. O. Ilchenko, P. G. Janson, K. J. Szabó, Chem. Commun. 2013, 49, 6614; c) N. O. Ilchenko, P. G. Janson, K. J. Szabo, J. Org. Chem. 2013, 78, 11087; d) J. M. Larsson, S. R. Pathipati, K. J. Szabo, J. Org. Chem. 2013, 78, 7330.

[21] a) C. Y. Legault, J. Prévost, Acta Crystallogr. Sect. E 2012, 68, o1238; b) V. Matoušek, E. Pietrasiak, R. Schwenk, A. Togni, J. Org. Chem. 2013, 78, 6763.

[22] P. Eisenberger, S. Gischig, A. Togni, Chem. Eur. J. 2006, 12, 2579.

[23] a) E. Lee, A. S. Kamlet, D. C. Powers, C. N. Neumann, G. B. Boursalian, T. Furuya, D. C. Choi, J. M. Hooker, T. Ritter,
Science 2011, 334, 639; b) J. R. Brandt, E. Lee, G. B. Boursalian, T. Ritter, Chem. Sci. 2014, 5, 169.

[24] a) N. Miyaura, A. Suzuki, Chem. Rev. 1995, 95, 2457; b) N. Miyaura, Top. Curr. Chem. 2002, 219, 11.

[25] D. J. Cram, J. Am. Chem. Soc. 1949, 71, 3863.

[26] a) G. A. Olah, R. D. Porter, J. Am. Chem. Soc. 1970, 92, 7627; b) G. A. Olah, R. D. Porter, J. Am. Chem. Soc. 1971, 93, 6877.

[27] R. Koller, K. Stanek, D. Stolz, R. Aardoom, K. Niedermann, A. Togni, Angew. Chem. Int. Ed. 2009, 48, 4332; Angew. Chem. 2009, 121, 4396.

[28] J. M. Larsson, K. J. Szabó, J. Am. Chem. Soc. 2013, 135, 443.

[29] C. Bour, J. Monot, S. Tang, R. Guillot, J. Farjon, V. Gandon, Organometallics 2014, 33, 594.

[30] I. Tellitu, E. Domínguez, Tetrahedron 2008, 64, 2465.

[31] A. C. Boye, D. Meyer, C. K. Ingison, A. N. French, T. Wirth, Org. Lett. 2003, 5, 2157. 